\title{
Understanding stakeholder preferences for flood adaptation alternatives with natural capital implications
}

\author{
Jonathon R. Loos ${ }^{1}$ and Shannon H. Rogers ${ }^{1}$
}

\begin{abstract}
Inland flood risks are defined by a range of environmental and social factors, including land use and floodplain management. Shifting patterns of storm intensity and precipitation, attributed to climate change, are exacerbating flood risk in regions across North America. Strategies for adapting to growing flood risks and climate change must account for a community's specific vulnerabilities, and its local economic, environmental, and social conditions. Through a stakeholder-engaged methodology, we designed an interactive decision exercise to enable stakeholders to evaluate alternatives for addressing specific community flood vulnerabilities. We used a multicriteria framework to understand what drives stakeholder preferences for flood mitigation and adaptation alternatives, including ecosystem-based projects. Results indicated strong preferences for some ecosystem-based projects that utilize natural capital, generated a useful discussion on the role of individual values in driving decisions and a critique of local environmental and hazard planning procedure, and uncovered support for a river management alternative that had previously been considered socially infeasible. We conclude that a multicriteria decision framework may help ensure that the multiple benefit qualities of natural capital projects are considered by decision makers. Application of a utility function can demonstrate the role of individual decision-maker values in decision outcomes and help illustrate why one alternative may be a better choice than another. Although designing an efficient and accurate multicriteria exercise is quite challenging and often data intensive, we imagine that this method is applicable elsewhere. It may be especially suitable to group decisions that involve varying levels of expertise and competing values, as is often the case in planning for the ecological and human impacts of climate change.
\end{abstract}

Key Words: ecosystem-based adaptation; flood; hazard planning; multicriteria decision making; stakeholder values; utility theory

\section{INTRODUCTION}

Floods cause almost $\$ 8$ billion in damage and 80 fatalities each year in the United States, making them the most damaging weather-related hazard in the country (based on 30-year averages; National Oceanic and Atmospheric Administration 2016). Inland flood risks are defined by a range of environmental and community factors, including land use and floodplain management (Wheater and Evans 2009). Shifting patterns of storm intensity and precipitation have been attributed to climate change and are exacerbating inland flood risks in regions across North America (DeGaetano 2009, Horton et al. 2014). Communities face the challenge of understanding how these changes influence their vulnerability to flood and of evaluating mitigation and adaptation efforts necessary to address them. Simultaneously, there is growing interest and research into how natural infrastructure, broadly referred to as natural capital, can be used for flood mitigation and adaptation efforts. These socalled ecosystem-based adaptation options may be less familiar to communities and decision makers, but they are becoming a viable option in a set of flood management alternatives.

Local stakeholders can be an important group to engage with during the implementation of adaptation strategies because they are more acutely aware of a community's specific vulnerabilities to climate change, as well as local economic, environmental, and social conditions (Wake et al. 2014). For several decades, there has been a call to integrate stakeholders into environmental management and decision making in more meaningful ways that go beyond public comment periods and public hearings (Gregory and Wellman 2001, Innes and Booher 2004). Stakeholders often have knowledge and understanding of their communities that outside experts do not possess, and many have debated the most appropriate methods for engaging with these communities. This is especially relevant for issues related to climate change adaptation. In a review of local, regional, and state decision makers in the United States, Brody et al. (2010) found a low level of consideration for climate adaptation in policy making and planning agendas. They suggest a need to better identify objectives for climate adaptation and to improve engagement with locallevel decision makers in doing so.

This paper focuses on local decision making in flood-prone communities of a large river basin in the northern New England region of the United States. Using a method of multicriteria decision analysis, we developed a workbook exercise to introduce stakeholders to four categories of local flood vulnerability and guide them through a decision process for selecting their preferred option to address each. In addition to testing a participatory method of structured decision analysis, a key goal of this work was understanding whether stakeholders hold preferences for some types of flood mitigation and adaptation alternatives over others. Specifically, the goal was to understand whether humanengineered options (bank armoring, flood control dams, etc.) or ecosystem-based approaches (river corridor zoning, wetland conservation, etc.) are more preferred for addressing unique flood hazards.

\section{Recognizing the role of ecosystems in adaptation efforts}

The use of natural capital to provide hazard mitigation benefits is compelling from an ecological and economic standpoint. There is growing international interest in the use of ecosystem-based projects to help alleviate pressures of land development, resource use, and biodiversity loss across the planet. Concepts such as Building with Nature (van den Hoek et al. 2014) and ecosystem- 
based adaptation (EBA; Munang et al. 2013) propose using natural infrastructure and ecosystem services to improve the resilience of human communities to natural hazards and climate change. By emphasizing the multiple benefits of ecosystem-based projects a compelling argument can be made for prioritizing them. Moreover, because natural capital freely exists, the concept of ecosystem-based projects appeals to those acting within a costbenefit framework. Justification for using ecosystem-based projects is strongest where good stocks of natural capital readily exist.

EBA is described as the use of natural capital to adapt to impacts of climate change, and it provides multiple cobenefits for mitigation, enhanced ecosystems, and protection of livelihoods (Munang et al. 2013). Maintaining and restoring wetlands for the many benefits they provide, including flood mitigation, is an often-used example of the potential of natural capital to provide EBA (Russi et al. 2013). EBA measures have been described as "no-regret" alternatives that meet adaptation objectives and provide a suite of cobenefits to make projects more cost-effective than built alternatives (Munang et al. 2013, Thieken et al. 2016). When considering EBA projects versus other alternatives, the benefits unique to EBA projects must be fully captured and presented during the decision-making process. This is especially true where decisions are made with public input and buy-in by diverse stakeholders is required. We address this challenge by including cobenefits as an attribute to consider in selecting public flood mitigation and adaptation projects.

\section{Including stakeholder input}

Public participation in environmental and urban planning has become a staple of decision making in the United States. Landmark federal legislation in the 1960s and 1970s, alongside emergence of participatory models of planning, have created an avenue for citizen and stakeholder input in community plan making (Godschalk et al. 2003, Hermans et al. 2007). Participation in environmental decision making has ranged greatly from simple public comment and hearing processes all the way to participatory action research. However, the former methods have left many stakeholders feeling dissatisfied with the participation process. As a result, environmental project planning is often plagued by low-level stakeholder acceptance and controversy surrounding scientific assessments and economic impacts (Gregory and Wellman 2001). Much research in the past few decades has focused on how to better engage the public and various stakeholders in meaningful ways. The National Research Council publication Understanding Risk advocated for a deliberative-analytic approach to decision making involving risk (Fineberg and Stern 1996).

Including stakeholders not just in the selection of alternatives but also in the design of project plans can capture a diversity of community values and promote buy-in of decision outcomes (Gregory and Wellman 2001). Through public participation, local knowledge can help to define community needs and hazard risks, and lead to better design of alternatives to address them (Seager et al. 2006, Simonovic and Akter 2006). Further, citizen stakeholders are best equipped to characterize the value of local natural resources and assess the true worth of changes to community risk factors because of their local knowledge and investment in the community (e.g., Sagoff 2000, Reed 2008,
Rogers et al. 2013). Additionally, local citizens play a role in town decision making, especially through the small-town New England approach of bottom-up management in the form of town meetings and planning boards staffed by citizens.

\section{Research setting and background}

Increasing flood risk has been identified as a pressing impact of climate change in Northern New England (Horton et al. 2014). Developing community plans and mitigation projects to prepare for growing flood risks will be subject to public participatory procedures. In case studies of five communities facing natural hazard risks and with exemplary models of citizen participatory planning, Godschalk et al. (2003) report that citizens expressed virtually no interest in natural hazards as a community problem and no interest in assisting planners to address hazards in comprehensive plans. The lack of interest is attributed to the perception of hazard mitigation as a technical issue and a lack of stakeholder experience with hazard events. They recommend that community planners better connect hazard mitigation with greater safety and quality of life, and develop more creative means for obtaining public input to hazard planning topics.

There is not a lack of personal experience with flood hazards in towns of the upper Connecticut River. Both states of Vermont and New Hampshire have a long history of riverine flooding and nationally declared storm disasters. Today the region is grappling with growing risks of extreme rain events and flood as a result of climate change. Providing for stakeholder participation in planning and selecting flood mitigation projects may generate a stronger understanding of existing flood vulnerabilities and promote support for community actions in addressing them.

It is with this background and motivation that we present a case study that tests a method of structured decision making to assess various options for addressing flood vulnerability, and does so using stakeholder input to inform project selections. In three stakeholder workshops we proposed realistic scenarios of flood vulnerability and asked participants to consider a set of options for alleviating each. We addressed the question of whether stakeholders have preferences for ecosystem-based versus humanengineered mitigation projects by comparing all projects across a common set of criteria, and included cobenefits as a criterion to convey ecosystem service or other hard-to-define benefits that often come with ecosystem-based projects. By having local stakeholders, i.e., planners, river commissioners, and citizens, individually navigate a decision process, we obtained an understanding of the factors they most care about when selecting preferred flood mitigation projects.

We asked stakeholders to use a ranking scheme to communicate project preferences and factors important to them in decision exercises. We then used multiattribute utility theory to calculate a utility value for each project alternative. From this, we could observe how individual decision-maker preferences drive the utility value of each alternative and compare utility value with actual stakeholder selections. Results generated a useful discussion on the role of individual values in driving decisions and a critique of local environmental and hazard planning procedure, and uncovered support for a river management alternative that had previously been considered socially unfeasible. 
Both the states of New Hampshire and Vermont have more than 16,000 miles of streams and rivers within their borders, making it no surprise that inland flooding is the most common natural disaster event in the region (New Hampshire Department of Safety 2013, Vermont Agency of Natural Resources 2014). In 2011, hurricane Irene brought more than $\$ 1.3$ billion in cumulative damage to the upper watersheds of both Vermont and New Hampshire along the Connecticut River corridor (Scarllet and Maillet 2014). The Connecticut River is the largest watershed east of the Mississippi River, and flows more than 600 miles from headwaters in Quebec through Vermont, New Hampshire, Massachusetts, and into the Long Island Sound in Connecticut. The Upper Valley (UV) is a $65 \mathrm{~km}$ stretch of river in the northern rural reaches of the Connecticut River watershed and includes towns in both Vermont and New Hampshire. Although the Connecticut River is highly manipulated by dams, the upper reaches of the watershed hold a relatively high number of freeflowing tributaries, creating seasonal changes in flow akin to natural flood regimes (Anderson et al. 2010). More than one such tributary meets the Connecticut in the UV, giving the region a history of frequent flooding. Because of its history and vulnerability to flooding, the UV is as an appropriate setting to test flood related decision making and develop a methodology applicable to flood-prone regions elsewhere.

\section{Research questions}

Working with communities in the Upper Valley (UV) of New Hampshire and Vermont, this study sought to (1) understand if stakeholder preferences exist for certain projects in preparing their community for future floods, (2) understand if those preferences support ecosystem- or natural capital-based projects, and (3) provide an example of how local stakeholder preferences can be assessed and potentially used in decision making in any geography.

\section{METHODS}

A spectrum of stakeholder participation-based methods of decision making has been developed and applied to environmental management decisions (Reed 2008). We sought to develop a framework that could evaluate individual decisionmaker values to select distinct flood mitigation and preparation project alternatives. Gregory and Wellman's (2001) application of a community-based evaluation tool in selecting estuary ecosystem management alternatives is informative here. In their study, a workbook was constructed to guide participants in selecting project-specific tradeoffs and eventual identification of best management options among a set of alternatives. They found this method to be effective at generating understanding of management options and enabling stakeholders to select alternatives that best support their values. With this work in mind, we developed a decision exercise for selecting flood planning alternatives.

To effectively compare different flood planning activities, we needed a format of decision analysis that can include diverse sets of information such as cost, environmental impact, effectiveness in reducing flood damage, and provision of cobenefits. Multicriteria decision analysis (MCDA) is one such method and provides a structured framework for assessing alternatives across a spectrum of criteria that have different scales of measurement. MCDA techniques are especially useful in decisions that involve diverse stakeholder interests and levels of knowledge. Using a transparent evaluation process, MCDA allows decision makers to visualize each factor involved with a decision and make selections based on criteria they deem most important. MCDA can promote identification of a most-agreed-upon course of action in group decisions (Kiker et al. 2005, Linkov et al. 2006, Mendoza and Martins 2006, Seager et al. 2006, Jordan and Turnpenny 2015). We developed a decision workbook using a multicriteria framework to lead stakeholders through a process to assess and select flood preparation projects.

We paired our multicriteria analysis with an assessment of project utility. Multiattribute utility theory (MAUT) offers a way of evaluating a decision scenario and assumes that a person most prefers alternatives perceived as being the most useful or providing the most utility to them. Methods of utility scoring use project attributes and decision-maker values to generate a utility score of decision alternatives (Linkov et al. 2006). We used a general utility function to generate utility scores for flood preparation alternatives and compare them with actual stakeholder project selections. Our six-step methodology for engaging with stakeholders, developing a multicriteria decision exercise, and obtaining data is outlined in Figure 1.

Fig. 1. Our methodology took place over the six steps denoted in bold text. Solid-lined arrows show progression of activities within each step. Dashed-line arrows show where information gathered during one step or activity directly informed another. MCDA indicates multicriteria decision analysis; MAUT, multiattribute utility theory.

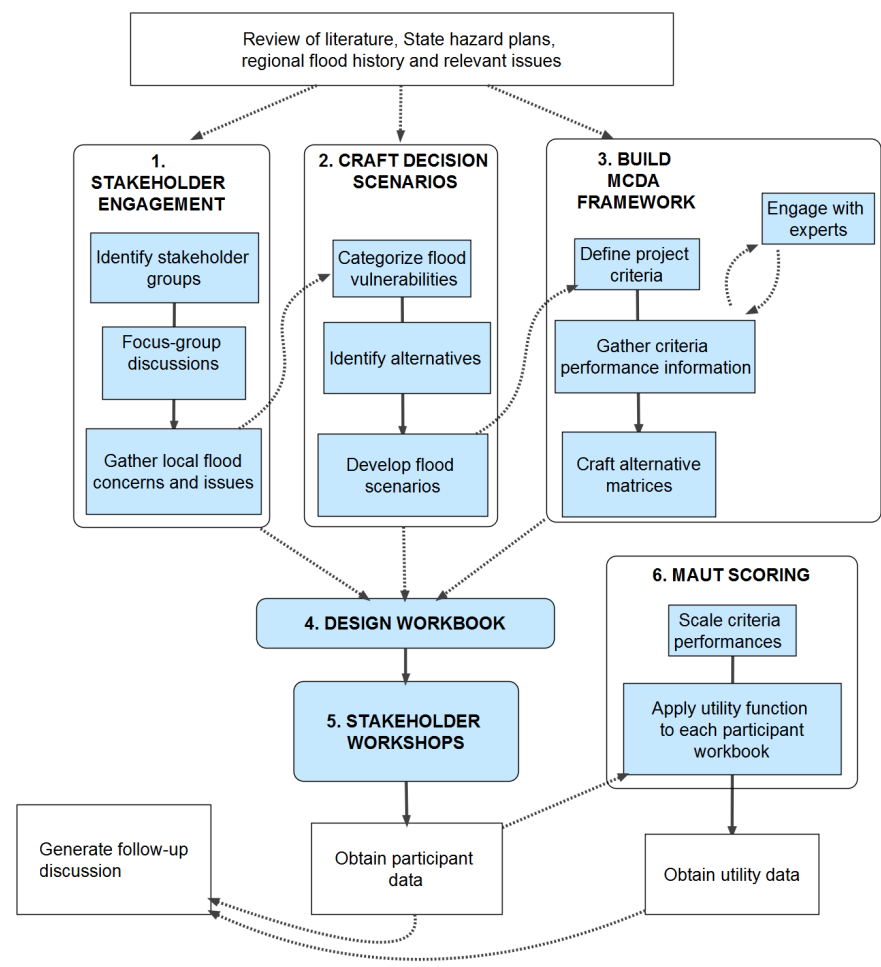




\section{Identification of issues and stakeholder groups}

We used a method of value-focused decision making to gather local flood concerns and distill a set of community objectives for addressing them (Keeney 1992). We engaged with two stakeholder groups considered to be knowledgeable of flooding in the UV: a regional river commission and a workgroup designated by the state government to advance community needs in adapting to climate change. A third stakeholder group of general citizens was also convened to capture nonprofessionally knowledgeable input. Through informal meetings and focus groups, we identified a range of flood topics of concern to stakeholders in the region and asked participants to discuss the actions their communities have taken or consider taking in addressing each (Table 1).

Table 1. Through focus groups and a public forum, we gathered flood issues of concern to Upper Valley stakeholders. We paired those concerns with a list of actions communities have implemented or discussed to address each. Input gathered from stakeholders directly informed the creation of decision scenarios to use in our workbook survey.

\begin{tabular}{|c|c|}
\hline $\begin{array}{l}\text { Stakeholder identified flood } \\
\text { concerns }\end{array}$ & $\begin{array}{l}\text { Stakeholder discussed actions for } \\
\text { addressing concerns }\end{array}$ \\
\hline Intense storm events & $\begin{array}{l}\text { Inventory and understand } \\
\text { vulnerabilities, improve resilience of } \\
\text { infrastructure, emergency response } \\
\text { programs }\end{array}$ \\
\hline Riverbank erosion & $\begin{array}{l}\text { Reinforcement of riverbanks, } \\
\text { deadwood reinforcement, } \\
\text { regulation of local dam operations, } \\
\text { river setback zoning }\end{array}$ \\
\hline Loss of river channel morphology & River channel realignment projects \\
\hline Management of floodplains & $\begin{array}{l}\text { Stronger regulation of floodplain } \\
\text { activities, reviewing town planning } \\
\text { process, restoring floodplain } \\
\text { habitats }\end{array}$ \\
\hline $\begin{array}{l}\text { Preserve community vision and } \\
\text { character }\end{array}$ & $\begin{array}{l}\text { Review of town planning process, } \\
\text { permitting of floodplain activities }\end{array}$ \\
\hline Stormwater management capacity & $\begin{array}{l}\text { Larger culverts, improve } \\
\text { infrastructure resilience }\end{array}$ \\
\hline $\begin{array}{l}\text { Role of climate change in future } \\
\text { flood }\end{array}$ & $\begin{array}{l}\text { Improve community understanding } \\
\text { of the impacts of climate change, } \\
\text { evaluate the "new normal" of flood } \\
\text { return periods }\end{array}$ \\
\hline $\begin{array}{l}\text { Connecticut River dam } \\
\text { operations management }\end{array}$ & $\begin{array}{l}\text { Participate in dam relicensing } \\
\text { process, request erosion studies }\end{array}$ \\
\hline
\end{tabular}

\section{Crafting decision scenarios}

New Hampshire's State Hazard Mitigation Plan organizes inland flood hazards into four sources. We used these four subheadings to frame community flood vulnerabilities and to deduce the specific actions communities may consider in addressing each type. Through an objectives hierarchy, we reduced the single problem of flooding into a set of primary flood vulnerabilities. Action lists gathered during stakeholder meetings provided the basis for this process, as did technical guidance published within New Hampshire's state hazard mitigation plan. Figure 2 illustrates the outcome of this process in an objectives hierarchy, where each of the primary flood vulnerabilities is distinguished and the objectives for addressing them are identified.
Fig. 2. Using stakeholder input and regional flood hazard plans, we created an objectives hierarchy to frame the decision scenarios for a workbook survey. An objective's hierarchy reduces an overall objective into fundamental objectives for achieving it. To do this, we organized flood vulnerability into four categories and then deduced primary actions that communities take to address those vulnerabilities.

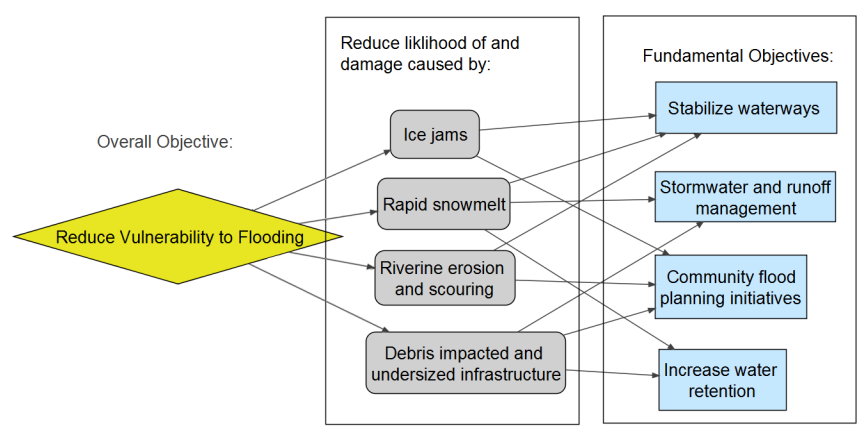

A means-end diagram reduces an objectives hierarchy into basic actions communities might take to achieve objectives (Fig. 3). At this point a decision scenario has been established; communities within our study area face flood risk from four primary sources, and a set of options, or alternatives, for addressing each type of risk exists. Included within those alternatives are both ecosystembased and human-engineered projects.

We designed a pen-and-paper exercise booklet, or workbook, to place participants in a hypothetical yet realistic scenario in which their community is planning to use community resources (time and money) to implement some flood mitigation or adaptation project for the public's benefit. We posed four decision scenarios that reflect the fundamental objectives identified in Figure 2. The entire workbook is available as a supplement to this article (Appendix 1).

\section{Defining criteria}

The core feature of multicriteria decision analysis is the evaluation of a set of alternatives by multiple attributes, referred to as criteria. Criteria may be communicated in qualitative or quantitative measures, and must be relevant to every alternative being considered (Keeney 1992). We consulted expert fluvial geomorphologists and community planners to inform the selection of seven criteria for evaluating our flood project alternatives: cost, effectiveness, environmental impact, cobenefits, project lifetime, social and political acceptance, and aesthetics. We then asked a different set of experts to evaluate each flood mitigation and adaptation alternative on how it performed/ scored/matched up on each of the seven criteria above by assigning a rank of low, moderate, or high to each or providing statistics on cost and other measures. Asking experts to consider project performances in qualitative terms was a fairly challenging task, and we had to acknowledge the limited ability of such rankings to fully capture the performance of each. We presented project alternatives and criteria performance measures in four matrices designed as table figures for the decision workbook (Fig. 4). 
Fig. 3. Means-end diagrams illustrate the ways flood vulnerabilities can be addressed through various projects and initiatives. Blue rectangles denote the four sources of flood vulnerability, and we reduced each into a set of alternatives by asking the question "How can this be achieved?" This process is repeated until actions are reduced down to the alternatives (hexagons) that can be

implemented as a means of achieving the objectives above. The alternatives selected are not meant to be an exhaustive list of options for each scenario. We chose certain human-engineered and ecosystem-based alternatives that are realistically being considered in the region. Bold-faced hexagons denote those considered as ecosystem-based alternatives.
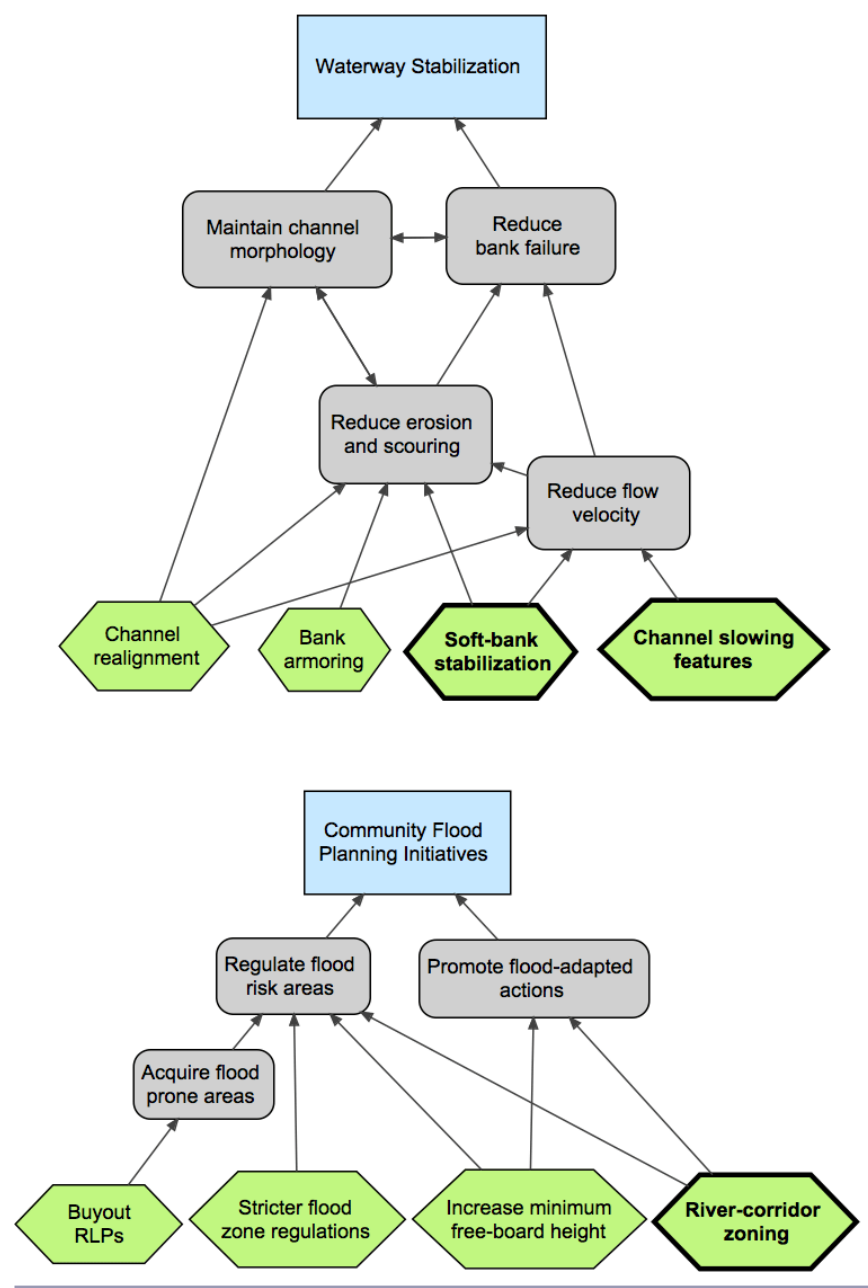

\section{Data gathering}

We organized and ran three workshops to implement the workbook exercise with stakeholder groups. Workshops began with an introductory presentation to briefly describe regional flood risks and the impacts of past flood events. We asked participants to consider a community decision scenario: "How should public resources be allocated to mitigate and prepare for flood risk?" The four flood scenarios and various alternatives were first introduced to participants as a group to provide time for questions prior to the workbook exercise.

In the workbook exercise, participants were asked to consider each flood scenario, evaluate project matrices, and rank alternatives from most to least preferred for implementation in their community. Following this, participants were asked to rank criteria from most to least important to consider in making their selection of preferred projects. Together, these responses give an
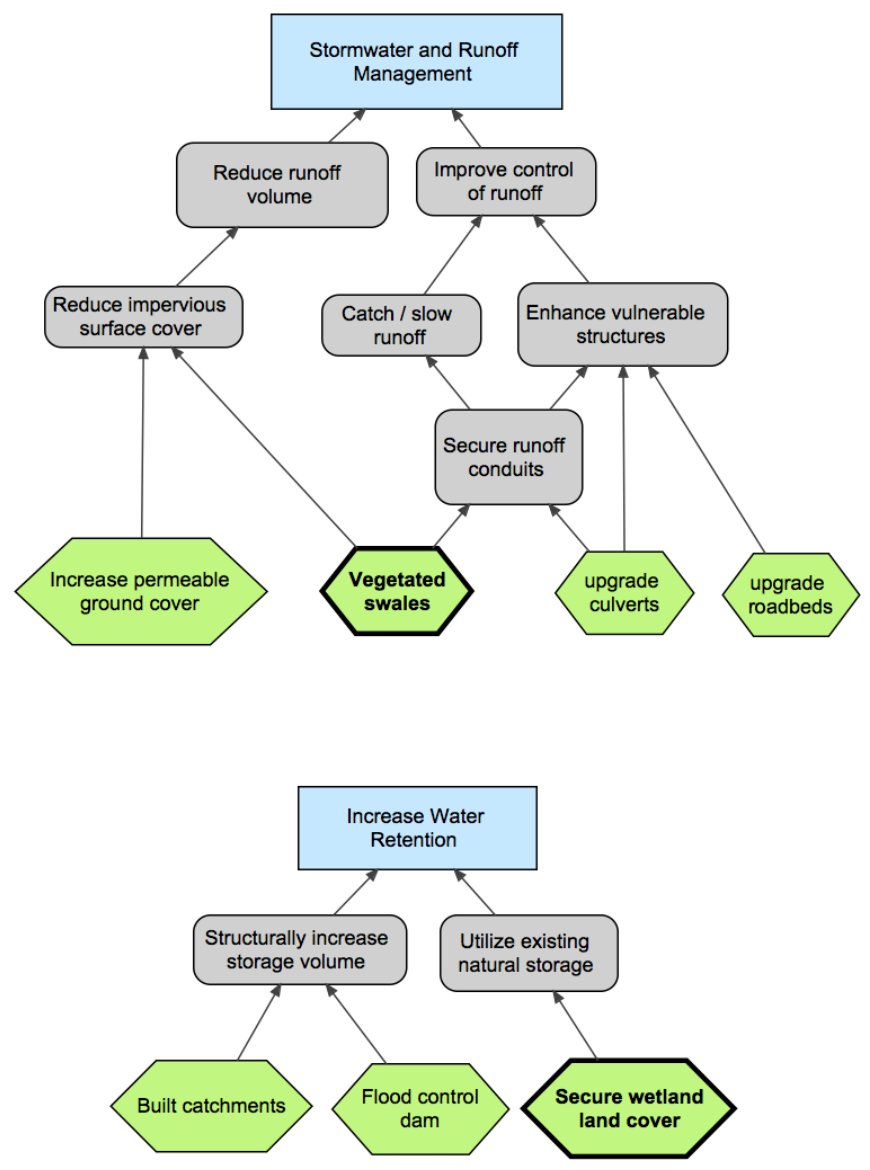

understanding of which projects an individual finds most preferential for each scenario and which criteria they deem most important to consider. This information was fed into a method of MAUT scoring that generates a measure of utility of each alternative for each participant. Follow-up discussions were initiated with a small group of participants and local planners after the workshops to obtain feedback on results and reactions to the methodology.

\section{Multiattribute utility scoring}

We applied an additive MAUT model described by Butler et al. (2001) and Kiker et al. (2005) to calculate utility values for each alternative (Eq. 1). The outcome is a utility score for each project tailored to each respondent's declared values as measured through weighting of criteria. Scores give a ranking of projects from greatest to least utility. Assumptions of preference and utility independence must be made for this model to be effective and are 
Fig. 4. Alternatives are presented in the workbook as a matrix, with each project in columns and the criteria by which to assess them in rows. We included photos in place of a qualitative measure of aesthetics so that participants could individually judge the aesthetic quality of each alternative. All four flood scenarios were translated into a similar matrix to present information in a multicriteria format in the workbook exercise.

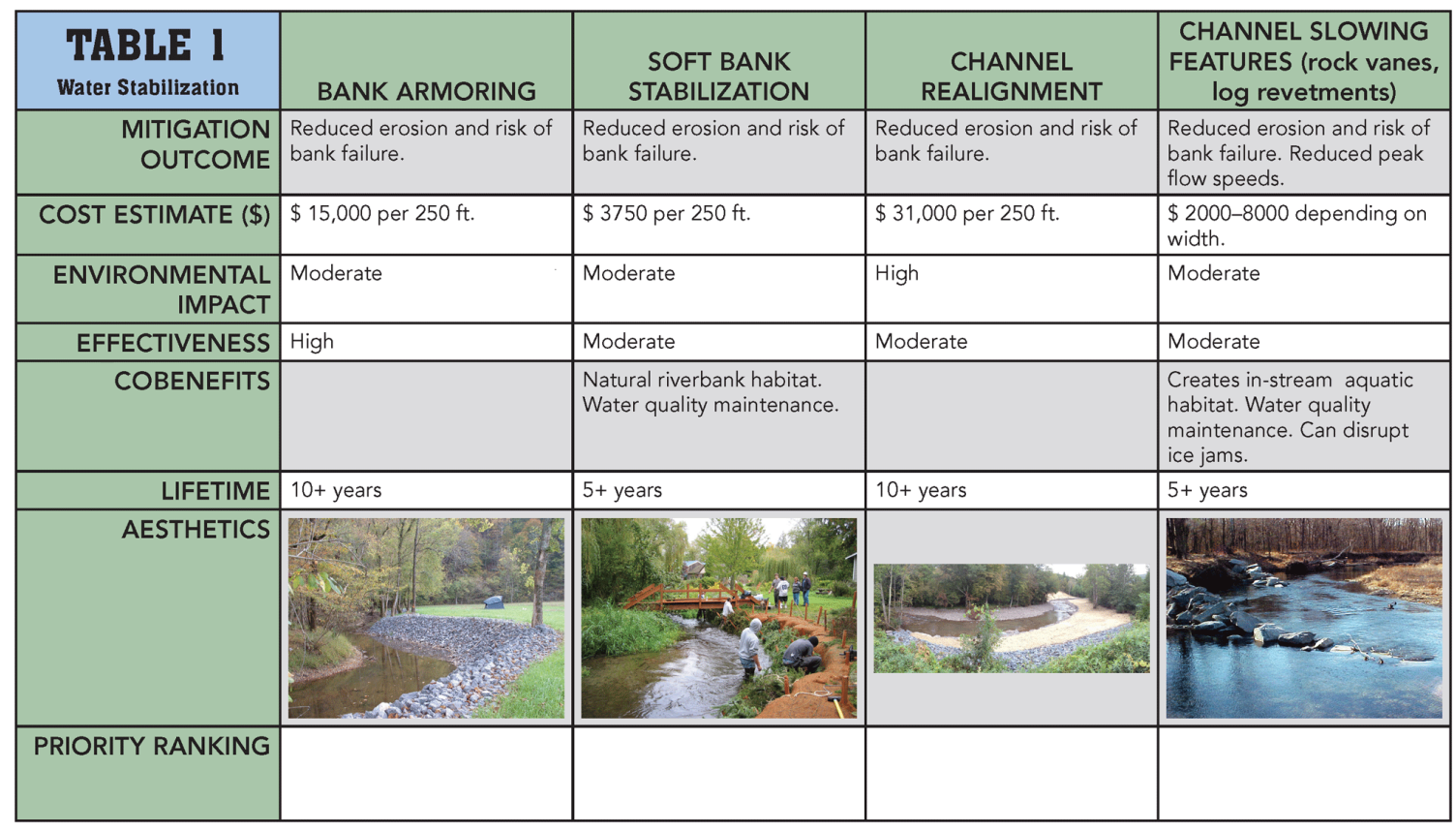

described in detail by Dyer (2005). Eq. 1 is a commonly used additive MAUT model:

$$
u(\mathrm{X})=\sum_{i=1}^{n} w_{i} u_{i}\left(\mathrm{X}_{i}\right)
$$

where $\mathrm{X}=\left(\mathrm{X}_{1}, \mathrm{X}_{2}, \ldots \mathrm{X}_{\mathrm{n}}\right)$ is an alternative being considered across a set of attributes $(i)$ with performance measures of $\left(u_{i}\right)$, and weight measures $\left(w_{i}\right)$ for each attribute (Butler et al. 2001). Thus $u(\mathrm{X})$, or the overall utility of alternative $\mathrm{X}$, is the sum of the products of performance and weight measures of alternative $\mathrm{X}$ on each attribute being considered in the scenario. Because this form of scoring is additive, it allows for high-scoring attributes to compensate for lower scoring attributes (Kiker et al. 2005). We applied this method by treating project criteria as attributes and converting the qualitative measures of each criterion to a scale of 0 to 1 , with 1 being a more favorable performance (Table 2). We used participants' ranking of criteria as weight values by converting them to a similar scale of 0 to 1 , with 1 being the most important criteria to a participant. Table 3 uses one participant's results to depict this utility scoring methodology.

\section{RESULTS}

A total of 18 stakeholders participated in our workshops with even representation of participants from both New Hampshire and Vermont. Nine participants identified themselves as holding some form of decision-making position in their town. Participants perceived their community's greatest risk of flood to
Table 2. Alternatives perform differently across each criterion. Although performances were presented in qualitative terms in the workbook matrices (low, moderate, high), they were converted to a scale of 0.33 to 1 for calculating a utility score. Values were assigned reflective of their qualitative measure, and a higher score denotes a more desired performance measure relative to others. For instance, it was assumed that decision makers desire alternatives with more cobenefits; thus, a performance measure closer to 1 was granted for alternatives providing more cobenefits. Inversely, it was assumed that decision makers prefer a lower cost, so a performance measure closer to 1 was granted for lower cost alternatives. In this way, performance measures closer to 1 signify a more desired criteria measure. The conversion of performance measures in this manner is shown for the waterway stabilization scenario.

\begin{tabular}{lcccc}
\hline \hline & $\begin{array}{c}\text { Bank } \\
\text { armoring }\end{array}$ & $\begin{array}{c}\text { Soft-bank } \\
\text { stabilization }\end{array}$ & $\begin{array}{c}\text { Channel } \\
\text { realignment }\end{array}$ & $\begin{array}{c}\text { Channel } \\
\text { slowing } \\
\text { features }\end{array}$ \\
\hline Cost & 0.66 & 1 & 0.33 & 1 \\
Impact & 0.66 & 0.66 & 0.33 & 0.66 \\
Effectiveness & 1 & 0.66 & 0.66 & 0.66 \\
Cobenefits & 0.33 & 0.66 & 0.33 & 1 \\
Lifetime & 1 & 1 & 0.66 & 0.33 \\
Aesthetics & 0.33 & 1 & 0.66 & 1 \\
\hline
\end{tabular}


Table 3. Shown here is a calculation of utility scores from one participant's workbook results using the utility function (Eqn. 1). The criteria ranking is obtained directly from a participant's workbook results, where criteria were ranked from most important (6) to least important (1). We divided each rank value by 6 to convert them to a 0 to 1 scale for use as weight values $\left(w_{i}\right)$ in the utility function. Utility scores were then calculated by multiplying weight $\left(w_{i}\right)$ with performance measures $\left(u_{i}\right)$ in Table 2 to generate a utility value of each alternative by each criterion. Values in each alternative's column are summed to obtain an overall utility value for each alternative. As scored for the participant above, soft-bank stabilization had the greatest utility (2.876), followed closely by bank armoring (2.768). Utility values are unitless measures, and a higher score conveys a more desired alternative to a participant.

\begin{tabular}{|c|c|c|c|c|c|c|}
\hline & $\begin{array}{c}\text { Criteria ranking } \\
\text { (W) }\end{array}$ & Weight conversion $\left(w_{i}\right)$ & $\begin{array}{c}\text { Bank } \\
\text { armoring }\end{array}$ & Soft-bank stabilization & Channel realignment & Channel slowing \\
\hline Cost & 4 & 0.666 & 0.44 & 0.666 & 0.22 & 0.666 \\
\hline Impact & 3 & 0.5 & 0.33 & 0.33 & 0.165 & 0.33 \\
\hline Effectiveness & 6 & 1 & 1 & 0.66 & 0.66 & 0.66 \\
\hline Cobenefits & 2 & 0.333 & 0.11 & 0.22 & 0.11 & 0.333 \\
\hline Lifetime & 5 & 0.833 & 0.833 & 0.833 & 0.55 & 0.275 \\
\hline Aesthetics & 1 & 0.166 & 0.055 & 0.166 & 0.11 & 0.166 \\
\hline Utility value & & & 2.768 & 2.876 & 1.815 & 2.431 \\
\hline
\end{tabular}

be posed by streams, brooks, or rivers and stormwater runoff. All participants agreed with the statement: "Local environmental factors such as land cover, riverbank structure, and wetland or forest areas play an important role in determining the severity of floods."

\section{Attribute weighting}

Table 4 shows the mean weight values for each criterion in all four decision scenarios. Weightings are ordered similarly in each; effectiveness and environmental impact are consistently highly weighted, followed by cost. Aesthetics was the lowest weighted criterion in all four scenarios. Cobenefits were also consistently assigned a low weight (average less than 2 of a maximum weight of 6) in all four scenarios.

Table 4. Results from participants' assignment of criteria weights for each decision scenario. Mean ranking values are reported for each criterion. A greater value indicates greater importance to participants in making decisions. Effectiveness was designated as the most important criterion in all four decision scenarios.

\begin{tabular}{lcccc}
\hline \hline Attribute & $\begin{array}{c}\text { Waterway } \\
\text { stabilization }\end{array}$ & $\begin{array}{c}\text { Runoff } \\
\text { manage- } \\
\text { ment }\end{array}$ & $\begin{array}{c}\text { Community } \\
\text { planning }\end{array}$ & $\begin{array}{c}\text { Water } \\
\text { retention }\end{array}$ \\
\hline Effectiveness & 3.6 & 3.27 & 4.5 & 3.38 \\
$\begin{array}{l}\text { Environmental } \\
\text { impact }\end{array}$ & 2.84 & 2.92 & 2.57 & 3.18 \\
$\begin{array}{l}\text { Cost } \\
\begin{array}{l}\text { Cobenefits } \\
\text { Lifetime }\end{array}\end{array}$ & 1.69 & 1.83 & 1.57 & 1.57 \\
$\begin{array}{l}\text { Social and political } \\
\text { acceptance }\end{array}$ & 1.3 & 1.32 & 1.37 & 1.38 \\
Aesthetics & 1.54 & 1.54 & - & - \\
\hline & 1.17 & - & 1.42 & 1.35 \\
\hline
\end{tabular}

\section{Multicriteria decision outcomes}

Participant rankings of alternatives in order of preference are reported for each of the four decision scenarios (Table 5). Ranking is in order of most preferred (1) to least preferred (4, or 3 for water retention alternatives).
Table 5. Participants ranked alternatives from most preferred (1) to least preferred ( 4 or 3 ) in each decision scenario. Mean and median preference ranking results are reported for each scenario. Alternatives with the greatest mean preference rankings were softbank stabilization, culvert upgrades, river corridor zoning, and wetland cover.

\begin{tabular}{llcc}
\hline \hline Decision scenario & Alternative & Mean & Median \\
\hline Waterway stabilization & Bank armoring & 2.67 & 3 \\
& Soft-bank stabilization & 1.92 & 1.5 \\
& Channel realignment & 3.25 & 4 \\
& Channel slowing & 2.17 & 2 \\
& features & & \\
Stormwater & Culvert upgrades & 1.92 & 1.5 \\
management & & & \\
& Roadbed upgrades & 3.17 & 3 \\
& Permeable ground & 2.42 & 2 \\
Community planning & Vegetated swales & 2.5 & 2.5 \\
& Increasing freeboard & 3.38 & 4 \\
& Floodplain regulations & 2.08 & 2 \\
& Buyout of RLP & 2.92 & 3 \\
& River corridor zoning & 1.62 & 1 \\
Water retention & Wetland cover & 1.23 & 1 \\
& Built catchments & 1.85 & 2 \\
& Flood control dam & 2.92 & 3 \\
\hline RLP indicates repetitive loss property. & & \\
& &
\end{tabular}

\section{Utility distributions}

An alternative's overall utility score is a sum of the utility derived from each criterion. Because alternatives perform uniquely on each criterion and because participants assign criteria weights differently, the distribution of utility across alternatives and criteria will differ among participants. Figure 5 illustrates this by presenting the overall utility of each alternative as derived from each criterion. This provides a way of visualizing the tradeoffs made when selecting one over another. For instance, selecting bank armoring over soft-bank stabilization would yield a gain in effectiveness for a loss of cost, cobenefits, and aesthetic value. Figure 5 uses the mean utility values from all participants. 
Fig. 5. Overall utility of each alternative is a sum of the utility factored from each criterion. As illustrated in this figure, the differences in performance and participant weights generates differing distributions of utility across criteria. Such a figure can aid decision makers in understanding where certain tradeoffs exist among alternatives and can contribute to a better decision outcome.
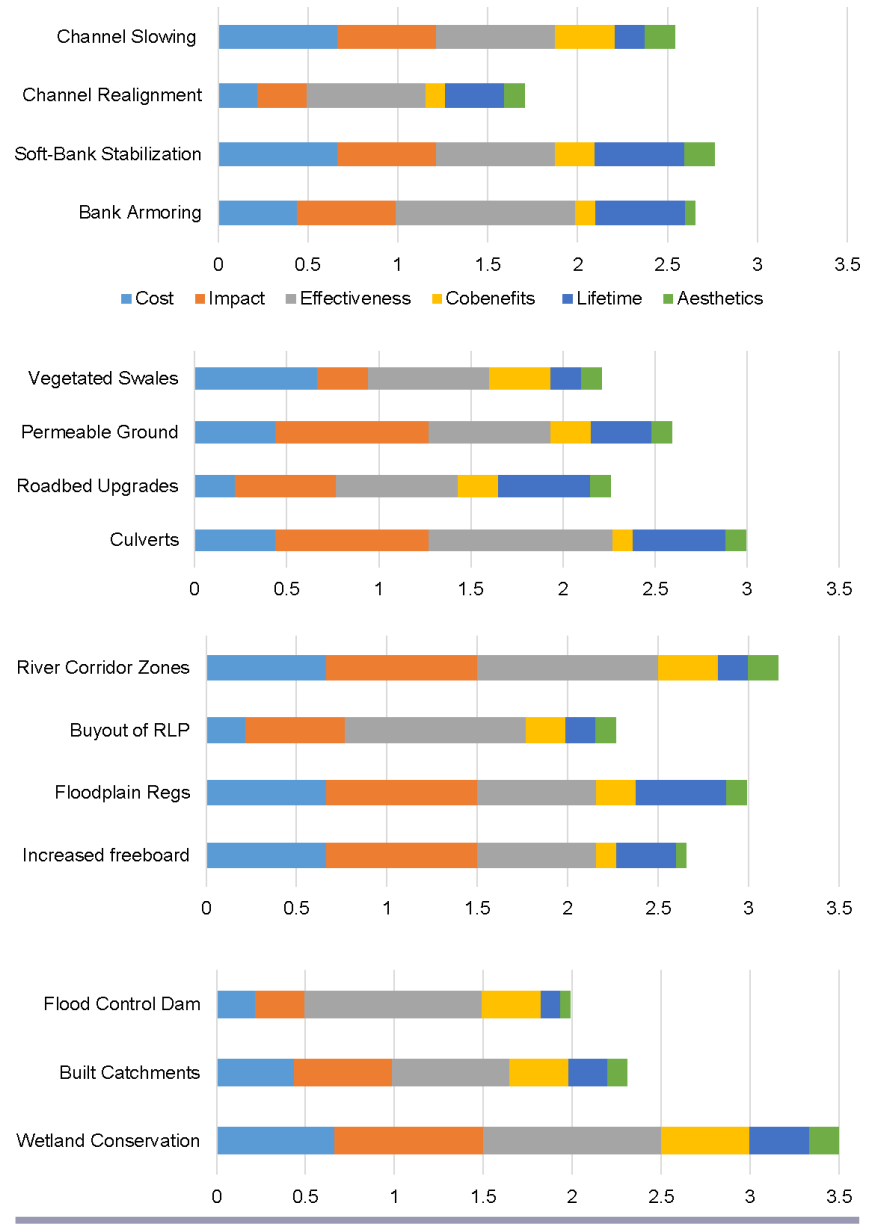

\section{DISCUSSION}

Workbook survey results, utility scores, and follow-up discussions provide the basis for discussion of our original research questions and insights that might be useful elsewhere.

\section{Do preferences exist, and what drives them?}

We found that preferences do exist for certain alternatives in addressing flood vulnerabilities. Although we have a limited set of information to ascertain the basis of preferences, they seem to be driven by a project's effectiveness and environmental impact, because these criteria were most highly weighted. The aesthetic attribute was consistently deemed least important. This suggests that participants view community funds as being justly spent on projects that aren't the cheapest option, or the best looking, as long as they're demonstrably effective and not overly impactful on the environment. Interestingly, expert stakeholders were surprised by these results and cite unfavorable aesthetics as the most commonly voiced complaint about public works by local citizens.

\section{Preferences for utility}

The most preferred alternatives were also those with the greatest calculated utility values. This indicates that participants were able to evaluate multiple criteria to select their best-choice alternatives. Strong preference for river corridor zoning in the community flood planning scenario was surprising to experts and may be illustrative of this method's ability to generate stakeholder buyin of otherwise contentious projects. Corridor zoning involves restricting development from a geomorphically defined width outside a river channel, known as a meander belt. By keeping river corridors undeveloped and unrestricted, a river's natural hydrologic processes can occur without causing human concern for erosion, flood, or changing channel morphology (Vermont Flood Hazard Area and River Corridor Rule; Vermont Agency of Natural Resources 2015). Implementing corridor zoning involves public acquisition of land and subsequent retreat from corridor land areas. Community planning experts felt that river corridor zoning was impossible to implement because of the socio-political atmosphere of the rural UV, despite it being the most effective manner to avoid flood damage. This type of sociopolitical influence on understanding climate-related issues is well documented (e.g., Hamilton et al. 2015). However, 69\% of completed workbooks selected corridor zoning as a most preferred option. Willingness to implement river corridor zoning may be greater than previously assumed and could be reevaluated as a flood preparedness measure.

\section{Ecosystem-based versus built measures}

Three of the four most-preferred alternatives (soft-bank stabilization, river corridor zoning, and wetland conservation) could be categorized as ecosystem-based projects. We cannot claim that they were preferred because of their ecosystem-based qualities, however, because each also had high utility scores.

In other studies, the appeal of ecosystem-based alternatives stems from their ability to provide multiple benefits and use freely existing natural capital to address vulnerabilities in ways that traditional built measure may not (Munang et al. 2013). We used cobenefits as a criterion to convey these advantages, and they ranged from habitat provision and water quality maintenance to recreational space, depending on the project. Overall, cobenefits were ranked as less important than effectiveness, impact, and cost in our scenarios.

Although our results cannot say for certain that ecosystem-based alternatives are preferred over human-engineered options, stakeholders do make a distinction between these types of projects, even if unknowingly. Dialogue from focus groups and follow-up discussions revealed that citizens, professional planners, and river commission groups describe natural or green alternatives (what we are referring to as ecosystem-based projects) as lower impact and even more preferable where possible.

In ideal situations stakeholders may push for ecosystem-based projects over other alternatives. However, ideal situations do not always exist, and other factors such as a pressing need for action, technical capacity, and availability of funds come into play. An example cited more than once is the need to stabilize an eroding 
riverbank quickly and effectively, especially when near infrastructure. Bank armoring by riprap (lining of a bank with concrete or rock rubble) can be implemented immediately to reduce erosion, quickly move high flows downstream, and provide dependable structural reinforcement, despite potentially negative implications for riparian habitat and downstream communities. Conversely, restoring riverbank structure through softbank stabilization takes longer to become fully functional. Although preferences exist for this approach, it may be difficult to justify when results are needed immediately and risk of further damage is high. Planners described this as one of the largest obstacles to risk and river management in the region. There is a clear distinction in objectives for river and flood management projects: maximize timeliness and structural control, or allow a tradeoff in such attributes to prioritize mitigation that is conducive to a river's natural hydrology, ecology, and geomorphic processes.

Cobenefits were cited as enhancing the bang-for-buck value of projects. As such, one stakeholder group described cobenefits as being an indicator of economic efficiency more than ecological attributes, and important to consider in cost-benefit-based decision making. Planning experts suggested that regional government action would be needed to make cobenefits an official consideration in public projects. This could begin with a framework for evaluating river management and flood mitigation alternatives in a multicriteria manner. Prioritizing the design of projects that reduce flood risk and complement natural riverine processes could cultivate a shared understanding of river management implications for flood vulnerability (Pahl-Wostl 2006). Otherwise, historical precedence and quick-fix solutions may continue to be implemented over other alternatives.

\section{Effectiveness as a structured decision-making tool}

By reducing a community's flood vulnerability into objective defined decision scenarios, and using a common set of criteria to evaluate solutions, we enabled participants to individually navigate a structured decision process. Modes of public participation in environmental governance are often criticized as being ineffective at incorporating citizen-stakeholder input (Gregory and Wellman 2001, Hermans et al. 2007). Our workbook format allowed for a two-way flow of information between facilitators and participants. A multicriteria format and ranking scheme provided information on participants' individual values and a way to identify best-choice alternatives among a group of stakeholders. The workbook was also a novel method of engagement for all participants and prompted them to consider local flood issues and decisions in a unique way.

Utility theory was useful for visualizing the way a project derives value from its performance across multiple criteria. Further, a utility function is a means to show the role of decision-maker values, as expressed through the weighting of criteria, in defining the usefulness of a project to an individual. By calculating utility scores from each participant's workbook, we could show that a particular alternative may not be equally useful to different actors. Overall, utility scores provide means for a logic-based assessment of alternatives and could assist in promoting stakeholder buy-in of public decisions.

\section{Insights for application}

In completing this exercise, participants generated discussion on personal values and their role in decisions. We imagine that a similar a framework could be used for a wide range of environmental decision scenarios and could provide means for a community to instigate dialogue on public decision problems. This could be especially useful where competing values are in play.

Enlisting local experts to identify alternatives and assign criteria performance measures is critical to ensuring credibility of this method. Having local actors involved in developing the workbook exercise likely helped generate trust and promote buy-in by local stakeholders (Gregory and Wellman 2001). This trust was key to encouraging thoughtful dialogue with workshop participants and local planners on flood vulnerability within the community. This enabled participants to discover they shared support for an alternative (river corridor zoning) that had been previously regarded as infeasible by community experts and prompted discussion on which obstacles needed to be addressed in making such an alternative work.

Application of a basic utility function provided a way to visualize criteria performance and differences in decision-maker values. Community experts suggested that our use of utility theory is an interesting academic exercise, but might be infeasible in municipal decision-making procedure. Developing a utility function requires technical organization that may be outside the administrative capacity of many community planning offices. However, we feel that a utility function only strengthens the ability of MCDA to parse out competing factors involved in a decision and can emphasize the fact that best-choice alternatives can differ from person to person. Acknowledging this may help stakeholders understand why those with differing environmental values or world views evaluate an alternative differently from them, and it can provide a basis to find common ground in a decision. For instance, not all stakeholders may assign the same level of value to ecological benefits provided by river corridor zoning. However, the value of river corridor zoning in avoiding flood damage may be more widely agreed upon and provide grounds for agreement.

\section{CONCLUSION}

Using a multicriteria framework, we designed an interactive decision exercise to enable stakeholders to evaluate alternatives for addressing specific community flood vulnerabilities. From three facilitated workshops, we conclude that preferences do exist for dealing with flood-related vulnerabilities, and those preferences may be driven by measures of effectiveness and environmental impact, and least influenced by aesthetics, in the case of our Upper Connecticut case study. Although we do not know how preferences might have been assigned without a multicriteria framework, the alignment of most preferred alternatives with those of greatest utility value suggests that our workbook methodology enabled participants to identify bestchoice alternatives, with best choice meaning the highest utility based on their preferences and the performance of various alternatives on the criteria of interest. Additionally, it ensured that the multiple benefit qualities of ecosystem-based projects were considered. Application of a utility function demonstrates the role of individual decision-maker values in decision outcomes and can help illustrate why one alternative may be a better choice than another. In testing this decision framework, we uncovered stakeholder willingness to implement river zoning, which had previously been considered as socially infeasible by community 
planners. Other methods of evaluating stakeholder preferences include public hearings and comment periods, large-scale surveys, and one-on-one interviews. The workshop approach allowed for interaction with the researchers in a more efficient manner than one-on-one interviews but with more depth than a large-scale survey. Additionally, public hearings and comment periods cannot often be structured in a manner that would elicit comparable preferences. Although designing an efficient and accurate multicriteria exercise is quite challenging and often data intensive, we imagine that this method is applicable elsewhere, and especially suitable to group decisions that involve varying levels of expertise and competing values, as is often the case in planning for the impacts of climate change.

Responses to this article can be read online at: http://www.ecologyandsociety.org/issues/responses. $\mathrm{php} / 8680$

\section{Acknowledgments:}

This work was made possible through the New Hampshire EPSCoR Program, supported by the National Science Foundation's Research Infrastructure Improvement Award \#EPS 1101245. Additional graduate assistantship support was provided by the Plymouth State University College of Graduate Studies and the Center for the Environment in Plymouth, New Hampshire. The success of stakeholder-engaged research is critically dependent upon the input of a whole range of actors, and we are incredibly grateful for the insights, support, and time donated by many in this project. Especially notable is the support of Sherry Godlewski from the New Hampshire Department of Environmental Services, Mark Green at the Center for the Environment, Richard Howarth at Dartmouth College, and the various Upper Valley region groups who participated in workshops and interviews.

\section{LITERATURE CITED}

Anderson, M. G., C. E. Ferree, A. P. Olivero, and F. Zhao. 2010. Assessing floodplain forests: using flow modeling and remote sensing to determine the best place for conservation. Natural Areas Journal 30:39-52. http://dx.doi.org/10.3375/043.030.0105

Brody, S., H. Grover, E. Lindquist, and A. Vedlite. 2010. Examining climate change mitigation and adaptation behaviours among public sector organisations in the United States. Local Environment 15:591-603. http://dx.doi.org/10.1080/13549839.2010.490828

Butler, J., D. J. Morrice, and P. W. Mullarket. 2001. A multiple attribute utility theory approach to ranking and selection. Management Science 46:800-816. http://dx.doi.org/10.1287/ mnsc.47.6.800.9812

DeGaetano, A. T. 2009. Time-dependent changes in extremeprecipitation return-period amounts in the continental United States. Journal of Applied Meteorology and Climatology 48:2086-2099. http://dx.doi.org/10.1175/2009JAMC2179.1

Dyer, J. S. 2005. MAUT-multiattribute utility theory. Pages 265-292 in S. Greco, M. Ehrgott, and J. R. Figueira, editors. Multiple criteria decision analysis: state of the art surveys.
Springer, New York, New York, USA. http://dx.doi. org/10.1007/0-387-23081-5_7

Fineberg, H. V., and P. C. Stern, editors. 1996. Understanding risk: informing decisions in a democratic society. National Academies Press, Washington, D.C., USA.

Godschalk, D. R., S. Brody, and R. Burby. 2003. Public participation in natural hazard mitigation policy formation: challenges for comprehensive planning. Journal of Environmental Planning and Management 46(5):733-754. http://dx.doi. org/10.1080/0964056032000138463

Gregory, R., and K. Wellman. 2001. Bringing stakeholder values into environmental policy choices: a community-based estuary case study. Ecological Economics 39:37-52. http://dx.doi. org/10.1016/S0921-8009(01)00214-2

Hamilton L. C., J. Hartter, M. Lemcke-Stampone, D. W. Moore, and T. G. Safford. 2015. Tracking public beliefs about anthropogenic climate change. PLoS ONE 10(9):e0138208. http://dx.doi.org/10.1371/journal.pone.0138208

Hermans, C., J. Erickson, T. Noordewier, A. Sheldon, and M. Kline. 2007. Collaborative environmental planning in river management: an application of multicriteria decision analysis in the White River Watershed in Vermont. Journal of Environmental Management 84:534-546. http://dx.doi.org/10.1016/j.jenvman.2006.07.013

Horton, R., G. Yohe, W. Easterling, R. Kates, M. Ruth, E. Sussman, A. Whelchel, D. Wolfe, and F. Lipschultz. 2014. Northeast. Pages 371-395 in Climate change impacts in the United States: the Third National Climate Assessment. In J. M. Melillo, T. C. Richmond, and G. W. Yohe, editors. 841 pp. U.S. Global Change Research Program, Washington, D.C., USA. http://dx. doi.org/10.7930/J0Z31WJ2

Innes, J. E., and D. E. Booher. 2004. Reframing public participation: strategies for the 21st century. Planning Theory \& Practice 5(4):419-436. http://dx.doi.org/10.1080/1464935042000293170

Jordan, A., and J. Turnpenny, editors. 2015. The tools of policy formulation: actors, capacities, venues and effects. New Horizons in Public Policy series. Edward Elgar, Northampton, Massachusetts, USA.

Keeney, R. 1992. Value-focused thinking: a path to creative decision making. Harvard University Press, Cambridge, Massachusetts, USA.

Kiker, G. A., T. S. Bridges, A. Varghese, T. P. Seager, and I. Linkov. 2005. Application of multicriteria decision analysis in environmental decision making. Integrated Environmental Assessment and Management 1:95-108. http://dx.doi.org/10.1897/ IEAM 2004a-015.1

Linkov, I., F. K. Satterstrom, G. Kiker, C. Batchelor, T. Bridges, and E. Ferguson. 2006. From comparative risk assessment to multi-criteria decision analysis and adaptive management: recent development and applications. Environmental International 32:1072-1093. http://dx.doi.org/10.1016/j.envint.2006.06.013

Mendoza, G. A., and H. Martins. 2006. Multi-criteria decision analysis in natural resource management: a critical review of methods and new modeling paradigms. Forest Ecology and Management 230:1-22. http://dx.doi.org/10.1016/j.foreco.2006.03.023 
Munang, R., I. Thiaw, K. Alverson, M. Mumba, J. Liu, and M. Rivington. 2013. Climate change and ecosystem-based adaptation: a new pragmatic approach to buffering climate impacts. Current Opinion in Environmental Sustainability 5:1-5. http://dx.doi.org/10.1016/j.cosust.2012.12.001

National Oceanic and Atmospheric Administration. 2016. Natural hazard statistics. National Weather Service, Silver Spring, Maryland, USA. [online] URL: http://www.nws.noaa.gov/om/ $\underline{\text { hazstats.shtml }}$

New Hampshire Department of Safety. 2013. State of New Hampshire multi-hazard mitigation plan. Concord, New Hampshire, USA. [online] URL: http://www.nh.gov/safety/ divisions/hsem/HazardMitigation/documents/hazard-mitigationplan.pdf

Pahl-Wostl, C. 2006. The importance of social learning in restoring the multifunctionality of rivers and floodplains. Ecology and Society 11(1):10. [online] URL: http://www.ecologyandsociety. org/vol11/iss 1/art10/

Reed, M. S. 2008. Stakeholder participation for environmental management: a literature review. Biological Conservation 141:2417-2431. http://dx.doi.org/10.1016/j.biocon.2008.07.014

Rogers, S. H., J. M. Halstead, and T. P. Seager. 2013. Characterization of public and stakeholder objectives in environmental management: New Hampshire's Lamprey River. Journal of Water Resources Planning and Management 139:217-222. http://dx.doi.org/10.1061/(ASCE)WR.1943-5452.0000246

Russi D., P. ten Brink, A. Farmer, T. Badura, D. Coates, J. Förster, R. Kumar, and N. Davidson. 2013. The economics of ecosystems and biodiversity for water and wetlands. IEEP, London, UK, and Brussels, Belgium; Ramsar Secretariat, Gland, Switzerland.

Sagoff, M. 2011. The quantification and valuation of ecosystem services. Ecological Economics 70:497-502. http://dx.doi. org/10.1016/j.ecolecon.2010.10.006

Scarlett, L., and E. Maillett. 2014. Using an ecosystem services management framework to pursue watershed-wide project priorities in the Silvio O. Conte National Fish and Wildlife Refuge and Connecticut River Watershed. U.S. Fish and Wildlife Service, Washington, D.C., USA.

Seager T. P., S. H. Rogers, K. H. Gardner, I. Linkov, and R. Howarth. 2006. Coupling public participation and expert judgment for assessment of innovative contaminated sediment technologies. Pages 223-244 in B. Morel and I. Linkov, editors. Environmental security and environmental management: the role of risk assessment. Springer, Amsterdam, Netherlands. http://dx. doi.org/10.1007/1-4020-3893-3 15

Simonovic, S. P., and T. Akter. 2006. Participatory floodplain management in the Red River Basin, Canada. Annual Reviews in Control 30:183-192. http://dx.doi.org/10.1016/j.arcontrol.2006.05.001

Thieken, A. H., H. Cammerer, C. Dobler, J. Lammel, and F. Schöberl. 2016. Estimating changes in flood risks and benefits of non-structural adaptation strategies - a case study from Tyrol, Austria. Mitigation and Adaptation Strategies for Global Change 21(3):343-376. http://dx.doi.org/10.1007/s11027-014-9602-3
Van den Hoek, R. E., M. Brugnach, J. P. M. Mulder, and A. Y. Hoekstra. 2014. Uncovering the origin of ambiguity in natureinclusive flood infrastructure projects. Ecology and Society 19 (2):51. http://dx.doi.org/10.5751/ES-06416-190251

Vermont Agency of Natural Resources, Department of Environmental Conservation, Watershed Management Division. 2014. State of Vermont 2014 water quality integrated assessment report. Montpelier, Vermont, USA. [online] URL: http://dec. vermont.gov/sites/dec/files/documents/WSMD_mapp_305b $\% 20 \mathrm{WQ} \%$ 20Report 2014.pdff

Vermont Agency of Natural Resources, Department of Environmental Conservation, Watershed Management Division. 2015. Environmental Protection Rule Chapter 29. Vermont Flood Hazard Area And River Corridor Rule. Montpelier, Vermont, USA. Adopted October 24, 2014; effective March 1, 2015. [online] URL: http://dec.vermont.gov/sites/dec/files/documents/wsmdfha-and-rc-rule-adopted-2014-10-24.pdff

Wake, C. P., C. Keeley, E. Burakowski, P. Wilkinson, K. Hayhoe, A. Stoner, and J. LaBranche. 2014. Climate change in northern New Hampshire: past, present and future. Paper 1. The Sustainability Institute, University of New Hampshire, Durham, New Hampshire, USA. [online] URL: http://scholars.unh.edu/ sustainability/1

Wheater, H., and E. Evans. 2009. Land use, water management and future flood risk. Land Use Policy 26:S251-S264. http://dx. doi.org/10.1016/j.landusepol.2009.08.019 


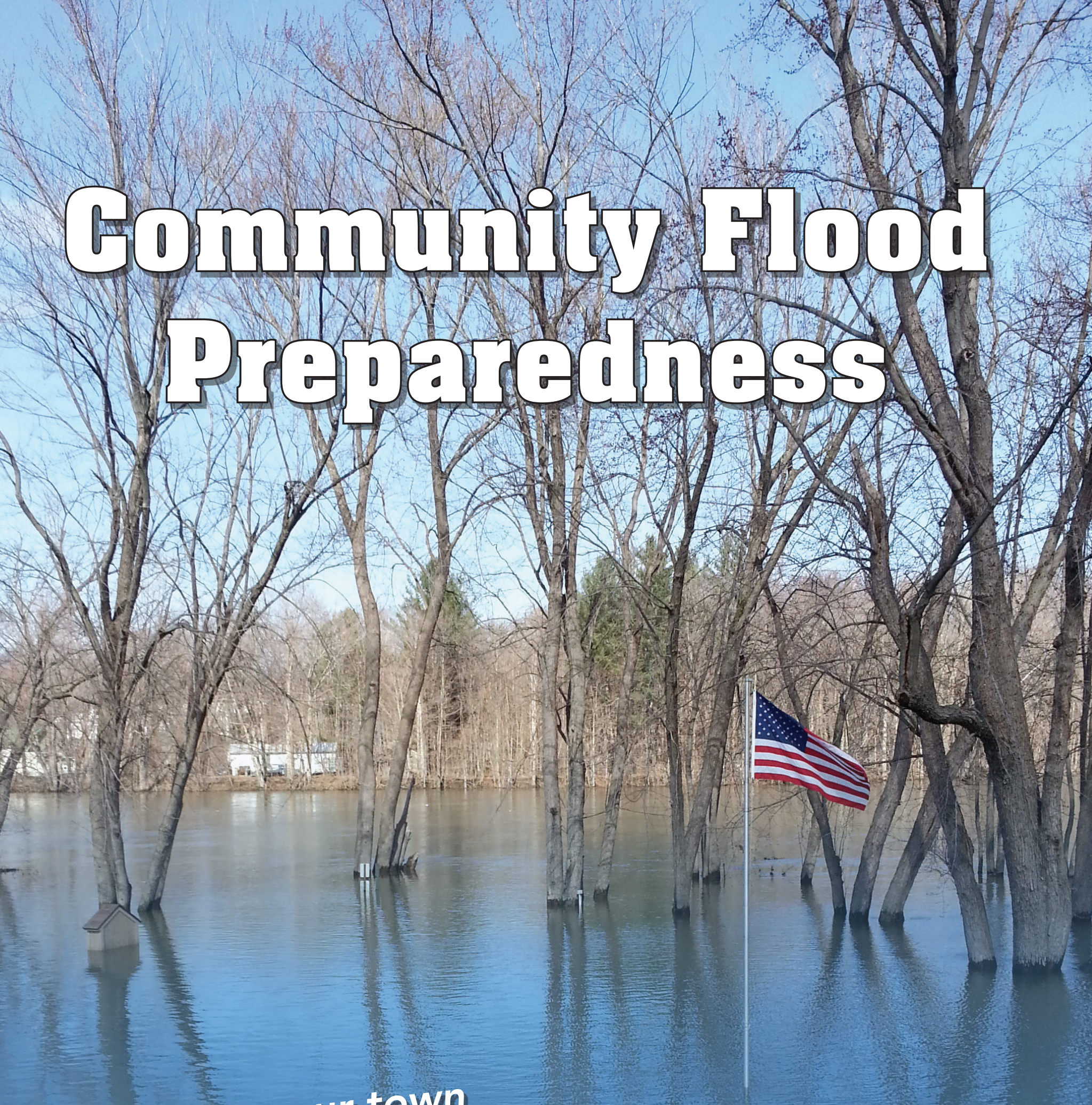

How can your town begin to adapt?

Principal Investigators: Jonathon Loos, M.S. Candidate Shannon Rogers, Ph. D.

Center for the Environment, Plymouth State University 

This workshop is part of a study on decision-making and flood preparation in Upper Valley communities. This workbook has been designed to gather your input to answer specific research questions. As a participant in this workshop, your involvement is central to this research. The intended outcome of this project is to provide a better understanding of how communities and policies in the Upper Valley, and other flood prone regions, can better support flood preparedness at the local level.

Please know that your time in this workshop is highly valued and appreciated. Don't hesitate to ask questions on any material at any time.

Thank you,

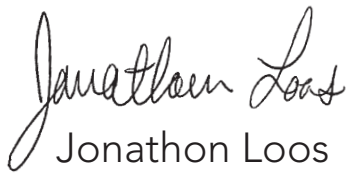

\section{VOLUNTARY PARTICIPATION}

I understand that my participation in this study is entirely voluntary, and that refusal to participate will involve no penalty or loss of benefits to me. I am free to withdraw or refuse consent, or to discontinue my participation in this study at anytime without penalty or consequence.

I voluntarily give my consent to participate in this research study. I understand that by choosing to provide responses to the questions in this workbook I am giving consent to use my responses for research at Plymouth State University. 


\section{BAGEGROUND INTORMATION}

1. Where do you live? Town/State:

(OR)

Prefer not to say.

2. How long have you been a resident of that town?
a. $0-5$ years
b. 6-15 years
c. More than 15 years

3. Did you consider the risk of flooding when making the decision to live in your current town?
a. Yes
b. No
c. Unsure

4. Do you perceive your community to be at risk of flooding?
a. Yes
b. No
c. Unsure

If answered (a. Yes) to question 4, please answer questions 4A and 4B:

4A. How do you perceive the risk of flood to your community today, compared to when you first moved there?
a. Greater today
b. Less today
c. About the same
d. Unsure

4B. In your community, would you suppose that the greatest risk of flood is posed by:

e. A large river, such as Connecticut River

f. Medium or small river, such as the Mascoma River

g. Streams or brooks

h. Stormwater or rain runoff

i. Other:

5. Has your own personal property (residence, vehicle, belongings, etc.) ever been damaged by flood or runoff waters?
a. Yes
b. No
c. Unsure

6. Please indicate to what level you agree with the following statement:

"Local environmental factors such as; land cover, riverbank structure, and wetland or forest areas play an important role in determining the severity of floods."
a. Strongly agree
b. Agree
c. Neutral
d. Disagree
e. Strongly disagree 


\section{MHTIGATION PROJEGTS}

The term 'mitigation' means to lessen the intensity, severity, or consequences of something negative. In planning for natural hazards, mitigation efforts aim to lessen the damage that results from a destructive event, such as a flood. The objective of flood mitigation projects is to reduce the amount of damage and loss from a flood. Oftentimes, flood mitigation projects work to enhance community structures and better manage the movement of water. As introduced in the presentation, mitigation projects may involve built improvements to community structures, as well as supporting natural features of a landscape.

The inserted page of tables present a range of projects that a community might undertake to reduce damage from future flood events. Projects are organized into two categories; those that contribute to waterway stabilization, and those that manage stormwater runoff. Projects in each table are presented with factors that might be considered when deciding whether to implement each. Please consider the flood preparation scenario below, and then use Tables 1 and 2 to answer the questions that follow.

\section{SCENARIO:}

Your community is looking for ways to reduce the level of damage and loss caused by the next flood. A $250 \mathrm{ft}$. segment of waterway in your area has been identified as especially vulnerable to erosion and collapse from high waters. Additionally, local stormwater structures and roads have experienced damage from runoff in past storms. Your town is considering waterway stabilization projects in TABLE $\mathbf{I}$ and runoff management projects in TABLE $\mathbf{2}$ to address these problems for the next flood event.

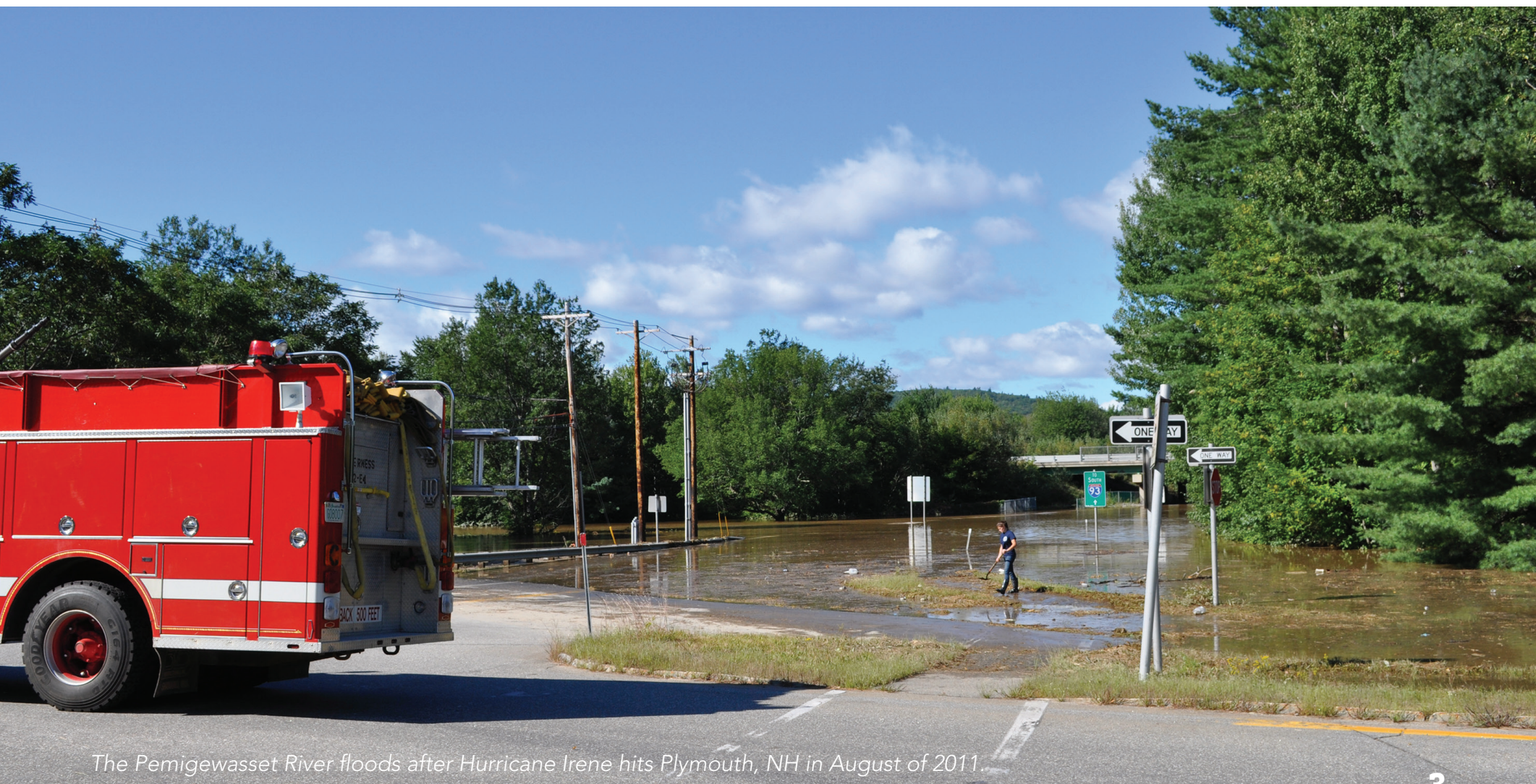




\section{MHTIGATION PROJEGTS}

1. Considering only Table 1, use the Priority Ranking row to indicate the priority that you would give each waterway stabilization project for implementation in your community. Use numbers "1" to indicate highest priority, "2" to indicate second highest priority, and so on for each project.

2. When deciding whether to implement the projects in Table 1, which criteria are most important to consider? Please indicate this with a rank from 1 (most important) to 6 (least important) of the criteria below.

Cost (\$)

Co-benefits

Environmental Impact

Effectiveness

Lifetime

Aesthetics

3. Of the projects presented in Table 1, is there one that should NOT be pursued by your community?

a. Yes. If yes, which one?

b. No

c. Unsure

4. Now considering only Table 2, please use the Priority Ranking row to indicate the priority that you would give each runoff management project for implementation in your community. Use numbers "1" to indicate highest priority, "2" to indicate second highest priority, and so on for each project.

5. When deciding whether to implement the projects in Table 2, which criteria are most important to consider? Please indicate this with a rank from 1 (most important) to 6 (least important) of the criteria below.

Cost (\$)

Co-benefits

Environmental Impact

Lifetime

Effectiveness

Aesthetics

6. Of the projects presented in Table 2, is there one that should NOT be pursued by your community?

a. Yes. If yes, which one?

b. No

c. Unsure 


\section{MHTIGATION PROJEGTS}

\section{MITIGATION GRANT ASSISTANCE}

There are a number of programs through state and federal offices designed to provide financial assistance to community flood mitigation projects. Those include the Pre-Disaster Mitigation (PDM) ${ }^{1}$ fund, the Flood Mitigation Assistance program², the Hazard Mitigation Grant Program, and the Repetitive Flood Claims and the Severe Repetitive Loss programs ${ }^{3}$, among others. These funds may provide up to $75 \%$ of a project's cost to a community.

The two tables below reflect the reduced costs of projects upon receiving potential grant funds. Please use them to answer question 7.

7. Considering the adjusted costs below alongside the criteria in Tables $\mathbf{1}$ and 2, does your prioritization of projects change for either table?

a. No

b. Yes. If yes, indicate new priority rankings in the "Revised Rank" row.

\begin{tabular}{|r|c|c|l|l|}
\hline $\begin{array}{c}\text { Waterway } \\
\text { Stabilization }\end{array}$ & $\begin{array}{c}\text { BANK } \\
\text { ARMORING }\end{array}$ & $\begin{array}{c}\text { SOFT BANK } \\
\text { STABILIZATION }\end{array}$ & $\begin{array}{c}\text { CHANNEL } \\
\text { REALIGNMENT }\end{array}$ & $\begin{array}{c}\text { CHANNEL SLOWING } \\
\text { FEATURES (Rock Vanes, Logs) }\end{array}$ \\
\hline $\begin{array}{r}\text { ADJUSTED } \\
\text { COST (\$) }\end{array}$ & $\$ 3,750$ per $250 \mathrm{ft}$. & $\$ 938$ per $250 \mathrm{ft}$. & $\$ 6,000$ per $250 \mathrm{ft}$. & $\$ 500-2,000$ depending on width. \\
\hline $\begin{array}{r}\text { REVISED } \\
\text { RANK }\end{array}$ & & & & \\
\hline
\end{tabular}

\begin{tabular}{|r|l|l|l|l|}
\hline $\begin{array}{r}\text { Stormwater } \\
\text { and Runoff } \\
\text { Management }\end{array}$ & $\begin{array}{c}\text { CULVERT } \\
\text { UPGRADES }\end{array}$ & $\begin{array}{c}\text { ROADBED } \\
\text { UPGRADES }\end{array}$ & $\begin{array}{c}\text { PERMEABLE } \\
\text { GROUND COVER }\end{array}$ & $\begin{array}{c}\text { URBAN } \\
\text { VEGETATED } \\
\text { SWALES }\end{array}$ \\
\hline $\begin{array}{r}\text { ADJUSTED } \\
\text { COST (\$) }\end{array}$ & $\begin{array}{l}\$ 1,500-4,000 \text { per } \\
\text { culvert. }\end{array}$ & $\$ 24,000$ per $1000 \mathrm{ft}$ of road & $\begin{array}{l}\$ 3,155 \text { per } 5,000 \text { sq. } \mathrm{ft} . \\
\text { lot (roughly the size of } \\
\text { a basketball court) }\end{array}$ & $\$ 1,125$ per $50 \mathrm{ft}$. \\
\hline $\begin{aligned} \text { REVISED } \\
\text { RANK }\end{aligned}$ & & & & \\
\hline
\end{tabular}


Adaptation to flooding involves preparing community structures and planning to better live with risk of flood for the long term. This includes structural upgrades as well as adopting community zoning ordinances that work to avoid or reduce damage from flood permanently.

A range of actions exist that can help a community better adapt to flood risk in the long term. Some of those actions are presented in Tables 3 and 4 in the following inserted page. Actions have been organized into two categories; those that involve community planning initiatives, and those that improve retention of excess water. Projects in each table are presented with attributes that might be considered when deciding whether to implement each. Please consider the flood adaptation scenario below, and use Tables 3 and 4 to answer the questions that follow.

\section{SCENARIO:}

Your community is trying to reduce its risk of damage from flood in the long term. Your state's Emergency Management Office and Floodplain Manager offer guidance on local planning and zoning initiatives that can reduce risk of flood damage to buildings in your town. Additionally, your town is considering investing in projects that can provide greater water retention, and reduce the height of floodwaters. The community planning initiatives being considered are presented in TABLE 3, and the improved water retention projects being reviewed are presented in TABLE 4.

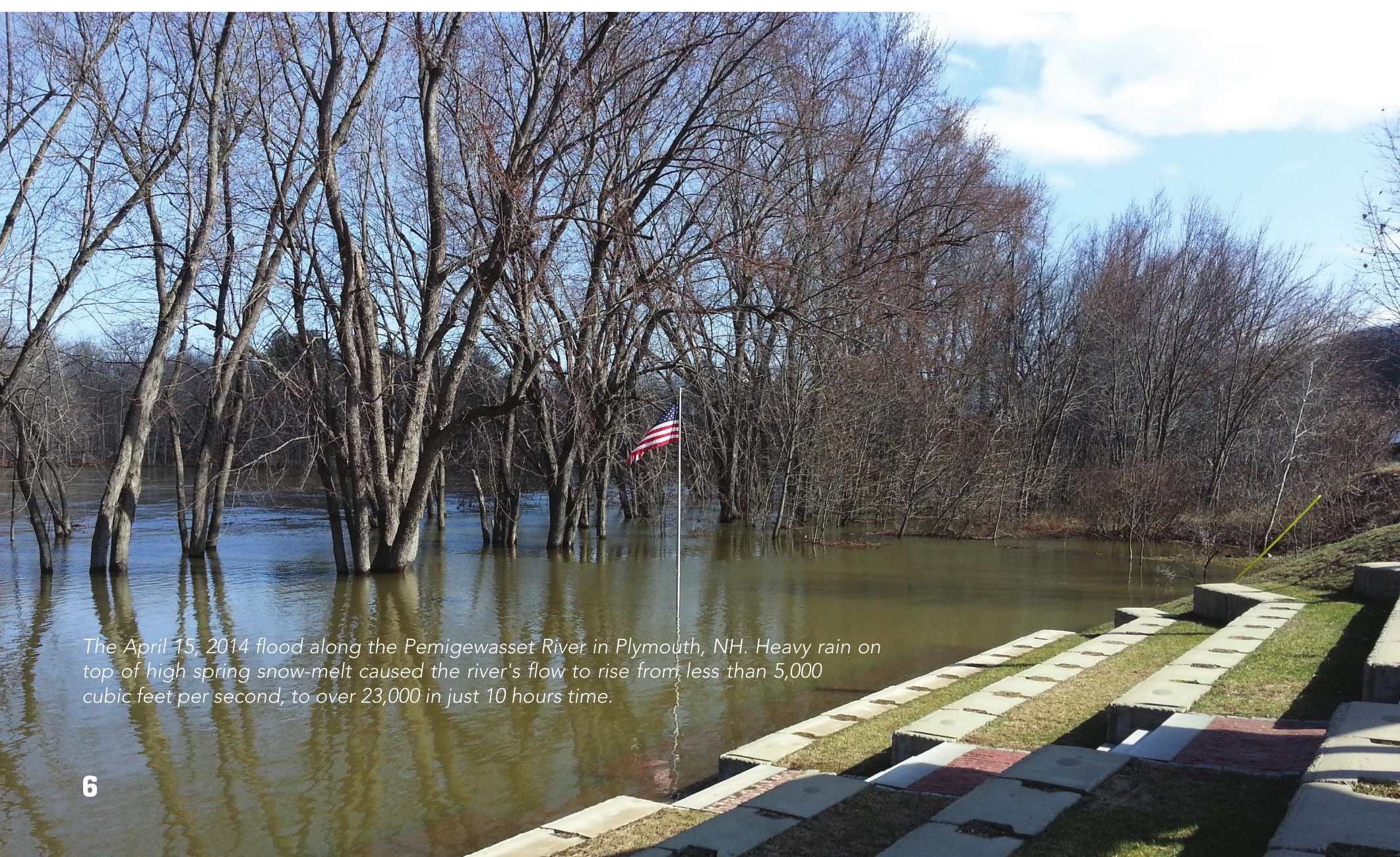




\section{BOMMUNTH ADAPTAHON TO FUTURF FLOOD BISK}

1. Considering only Table 3, use the Priority Ranking row to indicate the priority that you would give each initiative for implementation. Use numbers "1" to indicate highest priority, "2" to indicate second highest priority, and so on for each project.

2. When deciding whether to implement the projects in Table 3, which criteria are most important to consider? Please indicate this with a rank from 1 (most important) to 6 (least important) below.

Cost (\$)

Environmental Impact

Effectiveness
Co-benefits

Social and Political Acceptance

Aesthetics

3. Of the projects presented in Table 3, is there one that should NOT be pursued by your community?

a. Yes. If yes, which one?

b. No

c. Unsure

4. Considering only Table 4, use the Priority Ranking row to indicate the priority that you would give each project for implementation. Use numbers "1" to indicate highest priority, "2" to indicate second highest priority, and so on for each project.

5. When deciding whether to implement the projects in Table 4, which criteria are most important to consider? Please indicate this with a rank from 1 (most important) to 6 (least important) below.

Cost (\$)

Environmental Impact

Effectiveness
Co-benefits

Social and Political Acceptance

Aesthetics

6. Of the projects presented in Table 4, is there one that should NOT be pursued by your community?

a. Yes. If yes, which one?

b. No

c. Unsure

\section{FLOOD INSURANCE AND THE UPPER VALLEY}

The National Flood Insurance Program (NFIP) is a partnership between a community and the federal government. Communities participate by agreeing to adopt and enforce a floodplain management ordinance designed to reduce future flood risks. All residents in participating communities (whether in a floodplain or not) can purchase flood insurance. All Upper Valley communities currently participate in the NFIP, giving residents and businesses within each community access to flood insurance policies. ${ }^{4}$ The average annual cost for flood insurance in New England is around \$1,200, compared to around $\$ 1,500$ in the Upper Valley. ${ }^{5}$ 


\section{GOMMUNHT ADAPTATION TO FUTURE FLOOD RISK}

The community rating system (CRS) is a NFIP program that rewards communities for going beyond minimum NFIP requirements to prevent or reduce flood losses. Communities earn credit points that determine classifications. There are 10 CRS Classes: Class 1 requires the most credit points and provides the largest flood insurance premium reduction (45 percent), while Class 10 means the community does not participate in the CRS or has not earned the minimum required credit points, and residents receive no premium reduction. The CRS Classes are based on completion of 19 creditable activities that include various flood mitigation projects and initiatives. ${ }^{6}$

The adjacent table indicates the number of flood insurance policies in each Upper Valley town and the number of which are currently high-risk subsidized policies. Subsidized policies are subject to increase in the coming years.

\begin{tabular}{|l|c|c|}
\hline Town & $\begin{array}{c}\text { Total } \\
\text { Policies }\end{array}$ & $\begin{array}{c}\# \\
\text { Subsidized }\end{array}$ \\
\hline Plainfield, NH & 13 & 6 \\
\hline Lebanon, NH & 138 & 72 \\
\hline Hanover, NH & 33 & 8 \\
\hline Lyme, NH & 12 & 6 \\
\hline Orford, NH & 29 & 18 \\
\hline Piermont, NH & 1 & 0 \\
\hline Hartford, VT & 63 & 21 \\
\hline Norwich, VT & 30 & 22 \\
\hline Thetford, VT & 30 & 22 \\
\hline Fairlee, VT & 3 & 2 \\
\hline Bradford, VT & 9 & 6 \\
\hline
\end{tabular}

7. Please indicate to what level you agree with the following statement:

"I am concerned about the cost of flood insurance for properties in my town."
a. Strongly agree
d. Disagree
b. Agree
e. Strongly disagree
c. Neutral

8. The criteria below have been used to compare a variety of flood mitigation and adaptation projects in this workbook. Now considering the community rating system (CRS) described above how important is a project's CRS credit to consider when deciding which projects to implement?
a. Very important
d. Unimportant
b. Important
e. Very unimportant
c. Neutral

9. When deciding whether to implement any flood mitigation or adaptation project in your town, in general, which criteria are most important to consider? Please indicate this with a rank from 1 (most important) to 6 (least important) below.
Cost (\$)
Co-benefits
Environmental Impact
Aesthetics
Effectiveness
Credit towards CRS classification

10. Do you have flood insurance?
a. Yes
b. No 


\section{GONGHUDHE QUESHONS}

1. Please indicate to what level you agree with the following statement:

"Local environmental factors such as; land cover, riverbank structure, and wetland or forest area, play an important role in determining the severity of floods."

a. Strongly agree

b. Agree

c. Neutral

d. Disagree

e. Strongly disagree

2. [Optional] What projects and/or initiatives has your town undertaken to prepare for flooding, which you are aware of?

\section{DFMOGRAPHE IFORMAHION}

1. Do you hold a position as a decision maker in your community, region, or state? This may include positions in bodies of planning, permitting, review boards, committees/subcommittees, legislative, etc.

a. Yes

b. No

2. What is your highest level of education?
a. High school
b. Some college coursework
c. College degree
d. Professional degree
e. Advanced degree beyond college
f. Prefer not to share 


\section{PICTURE SOURGES}

blountlibrary.org/soil/

kitsapcd.org/

shandaken.us/disaster-prep-response/recovery-news/; Town of Shankaden

wildlifedepartment.com/fishing/streams/erosion.htm

dec.ny.gov/lands/; Scenic Hudson Organization

nh.gov/oep; Jennifer Gilbert

watershedmanagement.vt.gov/rivers/htm/rv_restoration.htm

enviroatlas.epa.gov/enviroatlas/InteractiveMapEntrance/InteractiveMap/

nae.usace.army.mil/Missions/CivilWorks/FloodRiskManagement/Vermont/UnionVillage.aspx

lakegeorgeassociation.org/what-we-do/Lake-friendly-Living/Permeable-Pavement.htm [porous asphalt] abbey-associates.com/splash-splash/picture_gallery.html

NEW HAMPSHIRE

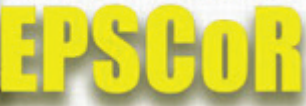

\section{Plymouth State}

U N I V E R S I T Y

CENTER FOR THE ENVIRONMENT

This research has been funded by NH EPSCOR, a program in the National Science Foundation for stimulating competitive research. Additional support has also been provided by the Center for the Environment and College of Graduate Studies at Plymouth State University. 